\title{
On Environmental and Architectural Design under New City Space View
}

\author{
Jinsong Tang \\ School of Art and Design, Jiangxi University of Technology, Nanchang Jiangxi, 330098, China
}

Keywords: New city, Space domain, Environmental and architectural design

\begin{abstract}
With national and social development, people's living standard improves and the requirement for living quality becomes increasingly high. Except leisure and recreation, cultural exchange is also required. For each family, both economic support and spiritual strength are needed. In this process, environmental and architectural design in new city space is very important. In modern cities with a large population, designers should not just carry out appearance design for environment and architecture, but pay attention to soul design to make cities meet people's spiritual demand in the development process and lay a good foundation for joint development of both the country and the people.
\end{abstract}

\section{Introduction}

With China's rapid development in recent years, architectural design has been in the spotlight during rapid development of each industry. Since relevant industries in China start and develop late, many shortcomings exist in urban architectural design. Both early construction and modern design cannot be compared with architectural design in other countries. Thus, relevant designers should realize the importance of this problem, fuse urban construction with people's life, make harmonious development of urban environmental and architectural design and lay a favorable foundation for urban development and construction while emphasizing external sense of beauty.

\section{Traditional city space and new city space}

\section{Traditional city space}

In the development process of city space, traditional city space and modern city space fall behind relatively. Compared with new city space, both cannot satisfy people's demand. Next, this paper simply describes traditional city space and modern city space.

\section{Traditional city space}

In the development process of traditional city space, the definition of city space falls behind. For city space, people just trade with goods in the space. In public places, people meet and know each other as well as gain information of some significant events in greeting process. Thus, they are the stages for people's mutual communication. Meanwhile, people will transport and trade goods they need in city space. People depend on single function of city space. People may enjoy the landscape during dating and use some functions of city space during chatting. After people introduce bicycles and cars in city life, the use efficiency and the scope of city space rise. As city traffic becomes developed, the use purpose of city space also changes gradually. But, traditional use function cannot be separated. The influence on people's spiritual world is small. Such development background did not change till the beginning of the last century when people started to sell goods at streets, and many shops were developed in city space. Meanwhile, an increasing number of bigger and bigger shopping malls and markets started to appear in city space, and even large shopping centers emerged. People altered their transaction activity to purchase anytime from traditional transaction. However, people were restricted much, and people's exchange was monitored by monitoring system. Public space was gradually transformed to private space in city development process. From the middle $20^{\text {th }}$ century, people's city space began to alter. Network technology is applied in each field, and people can gain the information they want without entry in city public space. In terms of communication and exchange, people could use telegram or mobile phone. Besides, people could walk in each city space through convenient traffic tools. 


\section{Modern city space}

Compared with traditional city space, modern city space is a very advanced public place. But compared with new city space, there are also many defects in modern city space. Firstly, in modern city space development process, convenient traffic also gives rise to many adverse effects on people's life. For example, the roads and parking lots occupy much public space; exhaust gas and noise of cars reduce the quality of public space; advanced city space fails to provide good spiritual life for people, but brings many troubles. People's public activity is restricted much. With the erosion of modern space, the quality of city space starts to decline. Relevant persons fail to realize the importance of city public space and living quality. When city public space is only limited to the function of developed traffic, city public space will not offer favorable spiritual environment for people. Secondly, some cities are abandoned in the development process. Relevant departments only pay attention to new city development and fail to well design public space construction for some old cities. Thus, the public space is ugly, and the architecture in city public space is common. Even, dangerous buildings will appear. Many adverse effects exist for people's life. People even cannot walk in public space. Hence, relevant departments should attach importance to these deserted cities, adopt effective measures to design public space of these cities and make efforts to meet people's living needs and spiritual needs. New city public space

From 1981, many countries started to attach importance to new city space, have ecological planning and architecture in cities and abandon traditional city public space design. Such architectural and environmental design is called green ecological design which improves architectural appearance design and creates good living space for people. In addition, foreign countries modify cities sharply. Automobile exhaust is released less in the city public space which is filled with vigor and passion and can better coordinate the relationship between city environment and ecology.

In new city space, the street is an important constituent part. Besides, the square is also a significant public activity place. Foreign countries have placed effective land utilization as a key project in city design in order to save public activity space and more rationally utilize the land. People's life is compact in cities. Based on improving life quality, it is required to enhance mutual exchange and communication, improve people's life quality and satisfy their spiritual world. People can not just hold large-scale activities in public space, but also have small-scale dating. Multi-level architectural design offers more convenient life for people. In accordance with foreign development of new city space, China starts to focus on design of city environment and architecture in order to create good living environment for people. In recent years, the state has just indulged in empty talk for transformation of discarded cities, without practical work. This not merely results in negative influence on people living in the discarded cities, but hinders national development. Thus, China should attach importance to design of city public space, promote city appearance and air environment, make people live in the good environment and lay a foundation for city development.

\section{Environmental and architectural design strategy under new city conditions}

In the process of new city space construction, relevant departments should focus on environmental renovation. City environment is important for people's survival, so designers should focus on the following in the design process.

\section{To pay attention to design of light environment}

In environmental and architectural design process of new city space, light design should be valued. The key point of day-lighting design is to control building density in a city. Relevant departments should scientifically and rationally stipulate building interval. At present, building density in some cities is large. Especially in prosperous districts, building density is so high that people's daily life is affected. They cannot gain sufficient light, which results in adverse effects on their health and daily life. Thus, designers should reasonably control building interval and make sunlight exposed in buildings $^{[1]}$. Meanwhile, glass should be designed on the building surface. If possible, glass curtain wall can be designed on buildings. Such glass can reflect sunlight on other buildings. However, in the design process, light reflection angle should be noticed to avoid light reflection on streets to affect 
drivers and pedestrians and result in traffic accidents. In addition, relevant departments should lay emphasis on high-level buildings, properly fuse buildings with other buildings in the city and avoid prominent buildings which will affect people's sense organs. Especially in some ancient famous cities, modern buildings should avoid. It is required to guarantee integrity of buildings in the ancient famous cities and keep original landscape during development of ancient famous cities. Designers should improve the beauty of city appearance and better develop the city in architectural design ${ }^{[2]}$.

\section{To pay attention to building site selection}

In the process of new city space construction, it is required to design site selection in architectural design. The following should be noticed in site selection process. Firstly, tall buildings should be set up in different places to avoid impacts on city environment due to high density of tall buildings. Secondly, site selection should be valued. During designing tall buildings, the influence of buildings on the city should be noticed. It is better to construct a symbolic building for the city to enhance the popularity. Thirdly, it is required to pay attention to economic benefit of architectural design. Based on ensuring scientific and rational site selection for buildings, economic benefit of the city should improve. In city construction process, it is required to focus on effectiveness of new city space and create favorable living environment for people.

\section{Architectural appearance design}

In the process of architectural design in the new city, it is required to attach importance to public space construction, scientifically design architectural appearance, and rationally control the influence of architectural appearance on city image. Firstly, the parameters of other buildings in the city should be collected, and the parameters of buildings in the city should be confirmed. Building space proportion design should be valued. Based on light demand, it is required to design architectural appearance, make sure the appearance meet people's spiritual needs and comply with space construction demand of a new city so that people can appreciate beautiful buildings in daily life. At the same time, architectural design should be effectively improved to make sure the design can boost appearance beauty, enhance people's aesthetic judgment and lay a foundation for better city development ${ }^{[3]}$.

\section{To improve relevant evaluation system}

In the process of new city space design, the fusion degree of buildings and city environment should be guaranteed. Relevant departments should improve relevant evaluation system, effectively supervise and manage architectural design. In this process, relevant departments may arrange professional personnel to evaluate the level of architectural design. The evaluation process can not just improve architectural design quality in cities, but also stimulate design desire of designers. In a bid to meet relevant design requirements, the following should be valued in the process of formulating evaluation standards. Firstly, whether architectural design fuses with environmental protection mechanism in cities? If architectural design meets requirements, designers should be rewarded and encouraged to ensure their better development. Secondly, design content of architectural design should be evaluated to make sure the appearance can meet relevant requirements. The beautiful appearance of buildings can not just improve overall city image, but also create favorable living environment for people ${ }^{[4]}$.

\section{To pay attention to design simplification}

At present, in urban architectural design process, some cities require designers to design novel buildings in order to create symbolic buildings. Some designers blindly refer to architectural design of other countries in order to enhance their popularity. In this way, external appearance of buildings cannot be improved, and city image will be negatively affected. Besides, city construction cost increases, and economic development of the city will suffer serious impacts. Thus, relevant personnel should attach importance to artistic value of architectural design in architectural design process, ensure design simplification, promote appearance beauty of architectural design, guarantee decrease in the cost input of urban architecture and fuse with other buildings in the city. Except fusion with urban architecture, buildings should be fused with natural landscape and architectural design rationality should be guaranteed in new city space development process ${ }^{[5]}$. 


\section{Conclusion}

In environmental and architectural design of new city space, relevant designers should well design streets and squares, and make sure people own free activity places while appreciating urban architecture. Some large-scale activity places and small-scale leisure places may be designed to satisfy people's spiritual demand and relieve their pressure in fast-paced life.

\section{References}

[1] Wang Jincan, Interpretation of Shenzhen Dongmen Business District Space Based on Space Syntax. Harbin Institute of Technology, 2012.

[2] Chen Yong, Hia Chen, Servitude Space of Architecture - Based on Elevated Balcony. Huazhong Architecture, 2015(6):20-24.

[3] Dai Yun, Du Chuangchuang, Analysis of High-rise Building Design and Urban Space Utilization. Architectural Engineering Technology and Design, 2015(20):586.

[4] Wang Lei, High-rise Building Design and Urban Space. New Silk Road Horizon, 2015(16):102-103.

[5] Ma Wanyu, Yu Ping, On High-rise Building Design and Urban Space. Urban Construction Theory Research (Electronic Edition), 2015(15):5709-5709. 